\title{
Aplikasi Simulasi Monte Carlo Dengan Teknik Antithetic Variates Dalam Menentukan Harga Opsi Cash-or-nothing Call
}

\author{
Ilham Syata \\ Prodi Matematika FST, UINAM, Ilham.syata@uin-alauddin.ac.id
}

\begin{abstract}
ABSTRAK, Monte Carlo method is the basis of all algorithms of the simulation method based on solving a problem to get better results by giving as many numbers of random numbers that generated and spread to normal standards. Antithetic variates method is one of the variance reduction methods to improve efficiency in Monte Carlo simulations. The problem of this research is how much the price of price of the European cash-or-nothing call option using Monte Carlo simulation with antithetic variates technique, and to check the accuracy of the results of the method calculated relative error, the smaller the relative error is, the more accurate the results obtained from the numerical method. By using the stock price data from the computed NASDAQ Composite with initial stock price (S0) of $\$ 8475.31$, strike price $(\mathrm{K})$ of $\$ 8470$, maturity (T) which is 1 year, interest free rate $(\mathrm{r})$ is $2.25 \%$, and volatility $(\sigma)$ is 0.1935467 , a number of simulations $(\mathrm{N})$ of 10.000.000, thus the price of NASDAQ European cash-ornothing call option NASDAQ Composite stock uses Monte Carlo method with an antithetic variates technique of $\$$ 0.497710 with an error of 0.000051. From several simulation experiments starting from 1.000, 10.000, $100.000,1.000,000$, and 10.000 .000 , it shows that the more simulations carried out, the more converging the results obtained to the analytical solution, the Black-Scholes Model is \$ 0.497735 .
\end{abstract}

Kata Kunci: Cash-or-nothing call European option, Monte Carlo Simulation, Antithetic Variates Technique

\section{PENDAHULUAN}

Produk derivatif merupakan suatu instrumen keuangan yang nilainya diturunkan dari harga underlying asset (asset yang mendasari). Produk derivatif terdiri dari futures, forward, swap, dan opsi [1]. Sedangkan, underlying asset terdiri dari bahan bangunan, emas, saham, dan lain-lain. Opsi merupakan suatu kontrak atau perjanjian dua pihak, di mana salah satu pihak memiliki hak (bukan kewajiban) untuk menjual atau membeli sebuah underlying asset dengan harga yang disepakati dan pada waktu yang telah ditetapkan [2]. Faktor-faktor yang memengaruhi harga opsi yaitu (a) waktu jatuh tempo adalah waktu berlangsungnya kontrak opsi berdasarkan kesepakatan, (b) volatilitas adalah besarnya fluktuasi harga underlying asset (Saham NASDAQ Composite) dalam suatu periode, (c) tingkat bunga bebas risiko, (d) harga kesepakatan / harga eksekusi (strike price) adalah harga jual atau harga beli yang telah disepakati dalam kontrak opsi selama berlangsungnya opsi, (e) dividen adalah bagian keuntungan perusahaan yang dibagikan kepada para pemegang saham, dan (f) underlying asset adalah aset dasar yang digunakan dalam menentukan harga opsi, aset dasar yang digunakan adalah saham NASDAQ Composite.

Banyak model dan metode yang telah ditemukan untuk menentukan harga opsi, seperti Model Black-Scholes[8,9,12], metode beda hingga upwind, metode elemen hingga, dan metode Monte Carlo (Monte Carlo Method). Metode Monte Carlo [2] adalah tipe simulasi probabilistik untuk mencari penyelesaiaan masalah dengan sampling dari proses random. Dasar metode Monte Carlo adalah mengadakan percobaan pada elemen-elemen probabilistik melalui sampling acak. Metode Monte Carlo merupakan metode untuk mengaproksimasi ekspektasi dari variabel acak menggunakan pembangkit bilangan pseudo-random. Dalam menganalisis metode Monte Carlo, peningkatan jumlah sampel akan mengurangi variansi. Untuk meningkatkan efisiensi dalam metode Monte Carlo diperlukan teknik variance reduction. Teknik ini terdiri dari importance sampling, control variate, conditional monte carlo, antithetic variates, stratified sampling, latin hypercube sampling, dan lain-lain [10]. Pada penelitian ini penulis mencari harga opsi cashor-nothing call tipe Eropa dengan simulasi Monte Carlo dengan ditambahkan teknik antithetic variates dalam reduksi varians.

\section{TINJAUANPUSTAKA}

\section{Opsi}

Opsi berdasarkan waktu pelaksanaannya terbagi menjadi dua, yaitu : 
1. Opsi Eropa (European Option) merupakan opsi yang memberikan hak kepada pemegangnya untuk mengeksekusi haknya hanya pada saat jatuh tempo $[1,3]$.

2. Opsi Amerika (American Option) merupakan opsi yang memberikan hak kepada pemegangnya untukmengeksekusi haknya pada atau sebelum jatuh tempo $[1,4]$.

Jenis-jenis opsi yaitu:

1. Opsi call adalah suatu kontrak atau perjanjian yang memberikan hak kepada pemegangnya untuk membeli sejumlah underlying asset dengan harga yang disepakati dan pada waktu yang telah ditentukan [1,5,13].

2. Opsi put adalah suatu kontrak atau perjanjian yang memberikan hak kepada pemegangnya untuk menjual sejumlah underlying asset dengan harga yang telah disepakati dan waktu yang telah ditentukan $[1,5,13]$.

3. opsi cash-or-nothing call merupakan kontrak atau perjanjian yang memberikan imbalan sebesar 1 satuan jika harga saham lebih besar dari harga kesepakatan (strike price) dan memberikan imbalan sebesar 0 jika harga saham lebih kecil harga kesepakatan.

4. opsi cash-or-nothing put merupakan kontrak atau perjanjian yang memberikan imbalan sebesar 1 satuan jika harga kesepakatan lebih besar dari harga saham dan memberikan imbalan sebesar 0 jika harga kesepakan (strike price) lebih kecil harga saham.

\section{Payoff Opsi Cash-or-nothing (CoN)}

Payoff adalah imbalan yang diperoleh dari kontrak opsi ketika opsi tersebut dieksekusi.

Payoff opsi cash-or-nothing $(\mathrm{CoN})$ tipe Eropa [6] yaitu

$$
\text { CoN }=B \times \mathcal{H}(S-K)
$$

dengan $\mathcal{H}$ adalah fungsi heaviside, $\boldsymbol{B}$ adalah konstanta.

Payoff opsi cash-or-nothing call (u) tipe Eropa yaitu

$$
\mathcal{H}(S-K)= \begin{cases}1 & , S_{t}>K \\ 0 & , S_{t}<K\end{cases}
$$

Payoff opsi cash-or-nothing put (p) tipe Eropa [7] yaitu

$$
\mathcal{H}(S-K)= \begin{cases}1 & , S_{t}<K \\ 0 & , S_{t}>K\end{cases}
$$

\section{Estimasi Return, Variansi dan Volatilitas Harga Saham}

Persamaan untuk menghitung return harga saham yaitu

$$
R_{t}=\frac{S_{t}-S_{t-1}}{S_{t-1}}
$$

Persamaan untuk menghitung variansi yaitu

$$
\text { var }=\frac{\sum_{i=0}^{n}\left(R_{i}-E[R]\right)^{2}}{n-1}
$$

Persamaan untuk menghitung ekspektasi return yaitu

$$
E(R)=\frac{\sum_{i=0}^{n} R_{i}}{n}
$$

Persamaan untuk menghitung volatilitas yaitu

$$
\sigma=\frac{1}{\sqrt{\tau}} \times \sqrt{\operatorname{Var}}
$$

\section{Harga Opsi dengan Simulasi Monte Carlo- Teknik Antithetic Variates}

Perhitungan harga opsi menggunakan teknik antithetic variates [11,12] mengikuti gerak Brown geometric dengan cara membangkitkan dua bilangan acak berdistribusi normal.

$$
\begin{gathered}
S_{T(1)}=S_{0} \cdot \exp \left(\left(\mu-\frac{\sigma^{2}}{2}\right) T\right. \\
+\sigma \varepsilon \sqrt{T})
\end{gathered}
$$




$$
\begin{gathered}
S_{T(2)}=S_{0} \cdot \exp \left(\left(\mu-\frac{\sigma^{2}}{2}\right) T\right. \\
-\sigma \varepsilon \sqrt{T})
\end{gathered}
$$

Dengan $S_{T}=$ harga asset pada saat jatuh tempo, $S_{0}=$ harga asset awal, $\mu=$ nilai harapan harga asset, $\sigma=$ volatilitas tahunan, $T=$ waktu jatuh tempo, $\varepsilon=$ bilangan acak yang menyebar normal baku $(\varepsilon \sim N(0,1))$.

Berdasarkan Persamaan (0.3) dan Persamaan (0.4), harga opsi $(\bar{u})$ dapat dihitung dengan menggunakan persamaan berikut

$$
\bar{u}=\frac{u_{1}+u_{2}}{2}
$$

Dengan,

$$
\begin{aligned}
& u_{1}=e^{-r T} \frac{1}{M} \sum_{i=1}^{M} A_{i} ; A_{i}=\left\{\begin{array}{l}
1, S_{T(1)_{i}}>K \\
0, S_{T(1)_{i}}<K
\end{array}\right. \\
& u_{2}=e^{-r T} \frac{1}{M} \sum_{i=1}^{M} B_{i} ; B_{i}=\left\{\begin{array}{l}
1, S_{T(2)_{i}}>K \\
0, S_{T(2)_{i}}<K
\end{array}\right.
\end{aligned}
$$

\section{Solusi Analitik Model Black-Scholes}

Solusi analitik model black-scholes untuk menentukan harga opsi cash-or-nothing call tipe Eropa yaitu

$$
u=e^{-r T} \cdot N\left(d_{2}\right)
$$

Dengan,

$$
\begin{gathered}
d 1=\frac{\ln \left(\frac{s_{0}}{k}\right)+\left(r+\frac{1}{2} \sigma^{2}\right) T}{\sigma(T)} \\
d_{2}=d_{1}-\sigma \sqrt{T}
\end{gathered}
$$

\section{Error Relatif}

Metode monte carlo dengan Teknik antithetic variates ini memperhatikan eror, rumus eror relative yang digunakan yaitu

$$
\text { eror }=\frac{|\widehat{\omega}-\omega|}{\omega}
$$

Dengan $\widehat{\omega}$ adalah nilai pendekatan metode numerik, sedangkan $\omega$ adalah nilai eksak yang diperoleh dari solusi analitik model BlackScholes [13].

\section{METODOLOGI}

Aset dasar yang digunakan adalah saham. Penulis menggunakan data harga saham penutupan dari perusahaan NASDAQ Composite yang dimulai dari tanggal 08 November 2018 08 November 2019 yang diperoleh dari http://finance.yahoo.com.

Langkah - Langkah yang akan dilakukan (0.9) dalam menentukan harga opsi cash-or-nothing call tipe Eropa menggunakan metode Monte Carlo dengan teknik antithetic variates sebagai berikut:

1. Memilih data harga saham NASDAQ composite

2. Melakukan uji normalitas pada data harga saham NASDAQ composite.

3. Menghitung nilai return dan variansi return harga saham NASDAQ Composite

4. Menghitung volatilitas harga saham NASDAQ Composite $(\sigma)$.

5. Menentukan tingkat bunga $(r)$

6. Menentukan harga kesepakatan/harga eksekusi (strike price) (K)

7. Menentukan waktu jatuh tempo (T)

8. Menentukan harga saham saat ini dari NASDAQ Composite $\left(S_{0}\right)$

9. Menghitung solusi analitik Model BlackScholes

10. Mensimulasikan harga saham NASDAQ Composite pada saat jatuh tempo $\left(S_{T}\right)$ dengan metode Monte Carlo dengan teknik antithetic variates.

11. Menghitung harga opsi cash-or-nothing call tipe Eropa dengan asumsi $\mathrm{B}=1$ satuan.

12. Menentukan eror relatif 


\section{PEMBAHASAN}

\section{Data Harga Saham}

Data yang digunakan merupakan data harga saham penutupan harian dari perusahaan NASDAQ Composite sebanyak 252 data.

Tabel 4.1 Harga Saham Penutupan NASDAQ Composite

\begin{tabular}{c|c|c}
\hline $\begin{array}{c}\text { Data } \\
(\mathrm{n})\end{array}$ & Harga Saham & $\begin{array}{c}\text { Return Harga } \\
\text { Saham }\end{array}$ \\
\hline 0 & $\$ 7570.75$ & - \\
\hline 1 & $\$ 7530.88$ & -0.005266 \\
\hline 2 & $\$ 7406.90$ & -0.016462 \\
\hline 3 & $\$ 7200.87$ & -0.027815 \\
$\cdot$ & $\cdot$ & $\cdot$ \\
$\cdot$ & $\cdot$ & $\cdot$ \\
251 &. & $\cdot$ \\
\hline 252 & $\$ 8475.31$ & 0.002840 \\
\hline
\end{tabular}

\section{Variansi Return Saham}

Nilai ekspektasi return $E(R)$ harga saham NASDAQ Composite yaitu:

$$
E(R)=\frac{\sum_{i=0}^{n} R_{i}}{n}=0.000522066
$$

Nilai variansi return harga saham NASDAQ Composite yaitu:

$$
\begin{gathered}
\operatorname{Var}=\frac{\sum_{i=0}^{n}\left(R_{i}-E[R]\right)^{2}}{n-1} \\
\operatorname{Var}=0.000148652
\end{gathered}
$$

\section{Volatilitas Harga Saham}

Setelah nilai variansi return harga saham didapatkan yaitu sebesar 0.000117539 dan nilai $\tau$ adalah $\frac{1}{252}$. Maka volatilitas harga saham dapat diperoleh sebagai berikut:

$$
\begin{gathered}
\sigma=\frac{1}{\sqrt{\tau}} \times \sqrt{\operatorname{Var}} \\
\sigma=\frac{1}{\sqrt{\frac{1}{252}}} \times \sqrt{0.000148652} \\
\sigma=0.1935467
\end{gathered}
$$

Jadi, nilai volatilitas harga saham NASDAQ Composite selama 252 hari ialah 0.1935467 .

\section{Tingkat Bunga}

Tingkat bunga yang digunakan adalah tingkat bunga Bank Amerika Serikat yaitu 2.25\%.

\section{Harga Saham Awal}

Harga saham Awal yang digunakan adalah harga saham perusahaan NASDAQ Composite tanggal terakhir (8 November 2019), maka harga saham saat ini ialah $\$ 8475.31$.

\section{Harga Kesepakatan (Strike Price)}

Untuk menentukan harga opsi cash-or-nothing call tipe Eropa dari underlying asset harga saham perusahaan NASDAQ composite yang diperdagangkan mulai 8 November 2018 sampai dengan 8 November 2019 diasumsikan harga kesepakatan yaitu $\$ 8470$.

\section{Waktu Jatuh Tempo}

Waktu jatuh tempo yang digunakan dalam kontrak Opsi ini adalah 1 tahun.

\section{Simulasi Monte Carlo dengan Teknik Antithetic variates.}

Dengan menggunakan parameter yang telah dihitung yaitu harga saham saat ini $\left(S_{0}\right)$ sebesar \$ 8475.31, waktu jatuh tempo $(T)$ yaitu 1 tahun, tingkat bunga $(r)$ yaitu $2.25 \%$, strike price $(K)$ sebesar $\$ 8470$, volatilitas $(\sigma)$ yaitu 0.1935467, banyak simulasi $(\mathrm{N})$, maka penentuan harga opsi cash-or-nothing call tipe Eropa menggunakan simulasi Monte Carlo

\begin{tabular}{|c|c|c|c|}
\hline $\mathrm{N}$ & MCAV & $\begin{array}{c}\text { Solusi } \\
\text { Analitik }\end{array}$ & Eror relatif \\
\hline $10^{3}$ & $\$ 0.498164$ & \multirow{5}{*}{$\$ 0.497735$} & 0.000861 \\
\hline $10^{4}$ & $\$ 0.497333$ & & 0.000808 \\
\hline $10^{5}$ & $\$ 0.497445$ & & 0.000583 \\
\hline $10^{6}$ & $\$ 0.497696$ & & 0.000079 \\
\hline $10^{7}$ & $\$ 0.497710$ & & 0.000051 \\
\hline
\end{tabular}
teknik Antithetic Variates (MCAV) sebagai berikut:

Tabel 4.2. Harga Opsi cash-or-nothing call tipe Eropa dengan teknik antithetic variates kecil maka harga Opsi cash-or-nothing call tipe Eropa menggunakan simulasi MCAV yaitu sebesar \$0.497710. 


\section{KESIMPULAN}

Berdasarkan perhitungan yang telah dilakukan diperoleh harga opsi cash-or-nothing call tipe Eropa dengan saham NASDAQ Composite menggunakan metode Monte Carlo dengan Teknik antithetic variates, diperoleh Harga Opsi cash-or-nothing call tipe Eropa menggunakan simulasi MCAV sebesar \$0.491092. Metode Monte Carlo dengan Teknik antithetic variates memiliki akurasi yang baik dengan memperbanyak jumlah simulasi dengan eror yang cukup kecil mendekati nol.

Adapun saran penulis yaitu untuk menghitung harga opsi dengan metode Monte Carlo dapat mencoba Teknik reduce variance lainnya seperti teknik importance sampling, conditional monte carlo, stratified sampling, latin hypercube sampling, moment matching dan lain-lain. opsi cash-or-nothing call

\section{DAFTAR PUSTAKA}

[1] M. N. Mooy, A. Rusgiono, and R. Rahmawati, "Penentuan harga opsi put dan call tipe eropa terhadap saham menggunakan model black-scholes," GAUSSIAN, vol. 6, no. 3, pp. 407-417, 2017

[2] D. P. Anggraini, D. C. Lesmana, and B. Setiawaty, "Aplikasi Simulasi Monte Carlo Untuk Menentukan Nilai Opsi Asia Dengan Menggunakan Metode Control Variate Pada Komoditas Pertanian," $J$. Math. Its Appl., vol. 16, no. 1, pp. 69-82, 2017.

[3] W. O. Irawan, M. Rosha, and D. Permana, "Penentuan Harga Opsi Dengan Model Black-Scholes Menggunakan Metode Beda Hingga Center Time Center Space (CTCS)," Eksakta, vol. 18, no. 2, 2017.

[4] S. E. Fadugba and C. R. Nwozo, "Mellin Transform Method for the Valuation of the American Power Put Option with NonDividend and Dividend Yields," J. Math. Financ., vol. 05, no. 03, pp. 249-272, 2015.
[5] I. Kamila, E. H. Nugrahani, and D. C. Lesmana, "Metode Monte Carlo Untuk Menentukan Harga Opsi Barrier Dengan Suku Bunga Takkonstan," J. Math. Its Appl., vol. 16, no. 1, pp. 55-68, 2017.

[6] S. Wang, "A novel fitted finite volume method for the Black-Scholes equation governing option pricing," IMA J. Numer. Anal., vol. 24, no. 4, pp. 699-720, 2004.

[7] M. Gao, "The British Binary Option," $J$. Math. Financ., vol. 9, pp. 747-762, 2019.

[8] A. Paliathanasis, K. Krishnakumar, K. M. Tamizhmani, and P. G. L. Leach, "Lie symmetry analysis of the Black-ScholesMerton Model for European options with stochastic volatility," Mathematics, vol. 4, no. 2, pp. 1-14, 2016.

[9] F. Black and M. Scholes, "The pricing of options and corporate 1," J. Polit. Econ., vol. 81, no. 3, pp. 637-654, 2008.

[10] P. Jäckel, Monte Carlo methods in finance, Wiley Finance. 2002.

[11] P. Glasserman, "Monte Carlo method in financial engineering," Quantitative Finance, vol. 4, no. 4. pp. 46-47, 2004.

[12] S. Ohsaki, J. Ruppert-Felsot, and D. Yoshikawa, $R$ Programming and Its Applications in Financial Mathematics. 2017.

[13] W. Ayudiah, D. C. Lesmana, and E. H. Nugrahani, "Penentuan Harga Opsi Sebagai Alat Lindung Nilai Petani Gabah Menggunakan Metode Monte Carlo Dan Teknik Control Variate," J. Math. Its Appl., vol. 16, no. 1, p. 39, 2017. 